\title{
Air flow through a non-airconditioned bus with open windows
}

\author{
S R KALE $^{1 *}, \mathrm{~S}$ V VEERAVALLI ${ }^{2}, \mathrm{H}^{\mathrm{D}} \mathrm{PUNEKAR}^{3}$ and \\ M M YELMULE ${ }^{1 \#}$ \\ ${ }^{1}$ Department of Mechanical Engineering, Indian Institute Technology Delhi, \\ New Delhi 110016 \\ ${ }^{2}$ Department of Applied Mechanics, Indian Institute Technology Delhi, \\ New Delhi 110016 \\ ${ }^{3}$ Fluent India Pvt. Ltd., Pune 411057 \\ e-mail: srk@mech.iitd.ernet.in
}

\begin{abstract}
Open window buses without air-conditioning are a major mode of urban and inter-city transport in most countries. High occupancy combined with hot and humid conditions makes travel in these buses quite uncomfortable. In this study air flow through a bus has been studied that could be the basis for low cost and ecofriendly methods of increasing passenger comfort and possibly reduce drag. The aerodynamics of such a road vehicle has not been studied as previous investigations have been confined to vehicles with closed windows that present a smooth exterior to air flow. Using a 1:25 scaled Perspex model of an urban bus in Delhi, flow visualization was performed in a water channel. The Reynolds numbers were onetenth of a real bus moving at $10 \mathrm{~m} / \mathrm{s}$. Smoke and tuft visualizations were also performed on an urban bus at $40 \mathrm{~km} / \mathrm{h}$. Numerical simulations were performed at the actual Reynolds number. Even though there were Reynolds number differences, the broad features were similar. Air enters the bus from the rear windows, moves to the front (relative to the bus) and exits from the front windows. Inside air velocity relative to the bus is about one-tenth of the free-stream velocity. The flow is highly three-dimensional and unsteady.
\end{abstract}

Keywords. Open window buses; urban transport; flow visualization; numerical simulation; passenger amenities.

\section{Introduction}

The bus is a major mode of public transport in most countries of the world, especially in urban areas. On per passenger per kilometer basis, the fuel economy is better and emissions are lower than either the automobile or motorized two-wheelers. A picture of a typical urban bus in Delhi is seen in figure 1. It consists of a box-shaped passenger compartment mounted

\footnotetext{
*Author for correspondence

${ }^{\#}$ Current address: GE India Technology Centre, Bangalore 560066
} 


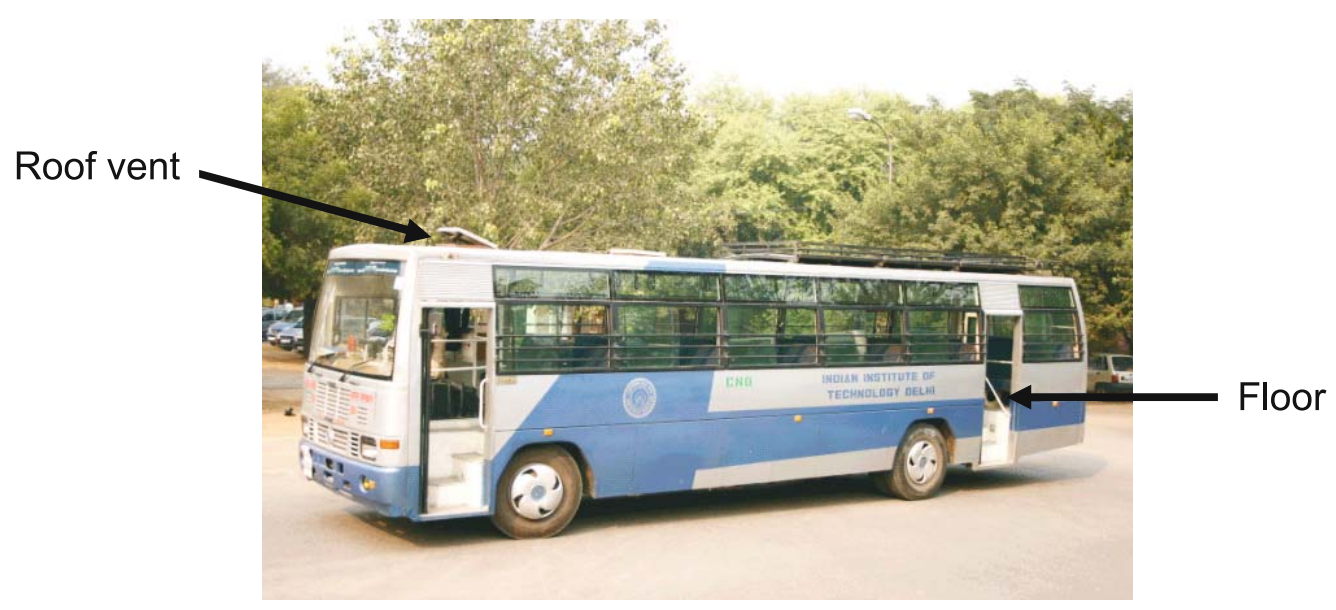

Figure 1. Picture of a typical non-airconditioned bus with open windows.

on a chassis powered by a compressed natural gas $(\mathrm{CNG})$ or alternately diesel fuelled engine. The compartment has two passenger doors (figure 1), a driver's door and an emergency door. A continuous row of windows is provided on both sides, that includes the doors in closed position also. While in motion, the passenger door(s) may or may not be fully open. Individual passengers adjust the window openings to suit their needs. Some buses have one or two adjustable openings on the roof ostensibly for augmenting air circulation (figure 1).

Almost all buses whether owned/operated by private or public enterprises, are not airconditioned, primarily to keep fares low. Consequently, the windows and doors are kept open so that air circulation induced by the motion of the bus will result in better comfort.

Although viewed as essential, bus services and buses are generally looked down upon for a variety of reasons. Passenger amenities in buses, such as seats and standing space, are inadequate and uncomfortable; they are noisy and vibrate. The climate of large regions in India, as also elsewhere in the world, is characterized by high ambient temperatures as well as high humidity for many months in a year. This aspect coupled with high passenger occupancy, also termed packing density, results in poor comfort levels inside the bus as quantified by air temperature, humidity and velocity. Window seats are at a premium and some passengers prefer traveling on the foot board or standing in the open doorway. This aspect is one of the major contributors to the perception of bus travel as uncomfortable.

The inside comfort can be improved with airconditioning which requires closing the windows; this is the basis of on-road airconditioned buses and the airconditioning equipment is roof mounted. Both the capital cost and running cost are more. Because of this aspect, and the need to keep fares low, it is unlikely that there will be a large scale conversion to airconditioned buses in the near term. Besides, such conversion would increase fuel consumption and add to emissions. Thus, bus travel which is the backbone of public transport in India will continue with non-airconditioned buses. It thus becomes imperative to improve comfort levels while relying on motion-generated circulation, or alternately from fans or blowers mounted inside the bus. The efficacy of roof openings has not been systematically studied. These design interventions are traceable to bus body builders who have little or no knowledge about vehicle aerodynamics. However, judicious placement of roof openings could be effective in augmenting inflow as well as being effective extractors and altering the flow. Studies 
on airflow around buses with closed windows can assist the design of airconditioned buses; however, it cannot be extended to open buses.

The aerodynamics of ground vehicles has been a subject of intense investigations that have focused largely on the automobile. In recent years, heavy vehicles, such as, trucks and buses have been the subject of aerodynamic studies with the aim of drag reduction and fuel economy improvement (Abdel Azim et al (1996), Kim (2004), Krajnovic and Davidson (2003), Lajos et al (1998), Saunders et al (1985)). A review of the aerodynamics of trucks, buses and trains is given in McCallen et al (2002). This review covers advances on important fluid mechanics aspects, such as, detached eddy simulation, as well as application specific studies. Both experimental and numerical simulations are presented. In all these studies, the vehicle windows are closed so that the external shape resembles a smooth closed body; there are no connections between the air inside and outside the vehicle. An exception to this configuration is seen in trucks where there is a gap between the cab and the body. Among the many aspects of flow over the vehicle, are studies on flow through the engine compartment (Nakanishi et al (2000), Ohshima (1998)). The aerodynamics of trains, particularly high speed trains, has been extensively studied; these studies, too, consider passenger compartments with closed windows and doors so that the exterior presents a smooth surface to outside airflow. The companion condition of coaches with open windows has not been studied. Findings from studies on closed passenger compartment with smooth exterior, experimental or computational, cannot be extended to the open window vehicles; there have been no studies on such vehicles.

At a practical level, there have been some innovations to improve passenger comfort in India. At least one state road transport corporation introduced wetted mats on an opening at the top front through which incoming air would get cooled. In another innovation, layers of straw (or khus) were applied to portions of the roof and kept moist. Both these techniques, especially the former, have tremendous potential to improve comfort level at low cost and in an eco-friendly manner.

In this paper, experimental and numerical investigations carried out on an open window bus are described. The results show interesting features some of which are quite counterintuitive. Visualization in a real bus was also performed. The agreement between numerical simulations and water channel visualizations as well as with visualization on the real bus provided consistent insights into the flow patterns. These studies, among the first for these vehicles, could become the basis for further investigations that could subsequently help bus body design with better ventilation. Advantages from such interventions would be better passenger comfort as well as possible reduction in aerodynamic drag. These changes could be part of a larger set of bus improvements and innovations that would lead to making bus travel more attractive and contribute to sustainable transport.

\section{Visualization experiments}

Flow visualization experiments were performed in a water channel, and since the Reynolds number was about an order of magnitude smaller than the real condition, visualization was also performed on a real bus itself. For water channel visualization a model was designed and to facilitate comparison with simulations, the same model was used there also. The geometry was kept realistic as well as simple to enable clear conclusions.

\subsection{Bus model}

The model was a scaled replica of the passenger compartment of the largest approved bus specifications for Delhi, $2.6 \mathrm{~m}$ wide $\times 1.9 \mathrm{~m}$ high and $11.5 \mathrm{~m}$ long. The floor height is $1.12 \mathrm{~m}$ 


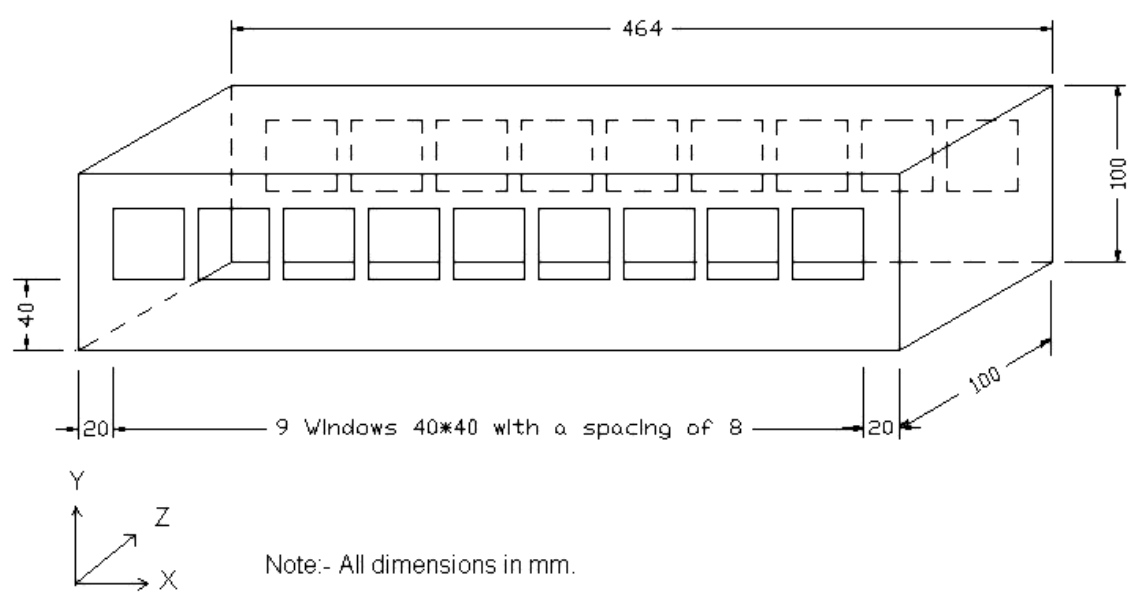

Figure 2. Drawing of the bus model.

above the road. Almost all new buses introduced after February 2002 in Delhi conform to these dimensions. Given the limitations of the water channel and wind tunnels available, it was not possible to replicate the same Reynolds number as in a real bus. With the limitations of blockage area, the maximum possible width was $100 \mathrm{~mm}$ and following geometrical modelling, the height was $100 \mathrm{~mm}$ and length $464 \mathrm{~mm}$; the resulting blockage was $7.7 \%$. The model was made of a $3 \mathrm{~mm}$ thick Perspex sheet.

Buses, in general, operate over a range of speeds. Urban buses are restricted to $40 \mathrm{~km} / \mathrm{h}$ $(11 \mathrm{~m} / \mathrm{s})$ and their movement is characterized by frequent halts at bus stops and traffic signals, as well as significant distances for acceleration and deceleration. Buses plying on inter-city routes and on highways cruise at speeds that are typically between 90 and $100 \mathrm{~km} / \mathrm{h}(25-$ $28 \mathrm{~m} / \mathrm{s}$ ). For these studies, the urban bus has been considered at a typical speed of $10 \mathrm{~m} / \mathrm{s}$. For a typical width of $2.5 \mathrm{~m}$, the Reynolds number is $1.6 \times 10^{6}$.

The bus body has several features that make it an open or semi-open construction, such as, windows with or without sliding glass, passenger door(s), driver's door, and emergency exits. These features coupled with the fact that passengers adjust the windows to their liking makes the openings unequal and/or asymmetric from a fluid dynamics viewpoint. Such a vehicle shape has not been the subject of any past investigations. The closest, if it can be said to be so, is the open freight railway wagon. While these features have to be studied, in the final analysis, it makes the air flow study quite complex. In this work, the body was modelled as a rectangular box without wheels or any internal features, such as, seats or passengers. The windows were modelled as square openings $40 \mathrm{~mm} \times 40 \mathrm{~mm}$. A total of nine window openings were provided on each side and they were directly opposite one another to maintain symmetry. The front and rear were completely closed. A dimensional sketch is shown in figure 2 and a picture of the model is shown in figure 3. Figure 2 also shows the coordinate axes used here to describe the flow $-x$ denotes the direction of the free stream (bus fixed); $y$ is the direction perpendicular to the ground; and $z$ is the transverse direction. The plane $y=0$ corresponds to the ground location while the plane $z=0$ is the plane of symmetry. This shape results in a well-defined geometry and enables a well-controlled study of the major aerodynamic features. This geometry also makes it convenient for numerical simulations. 


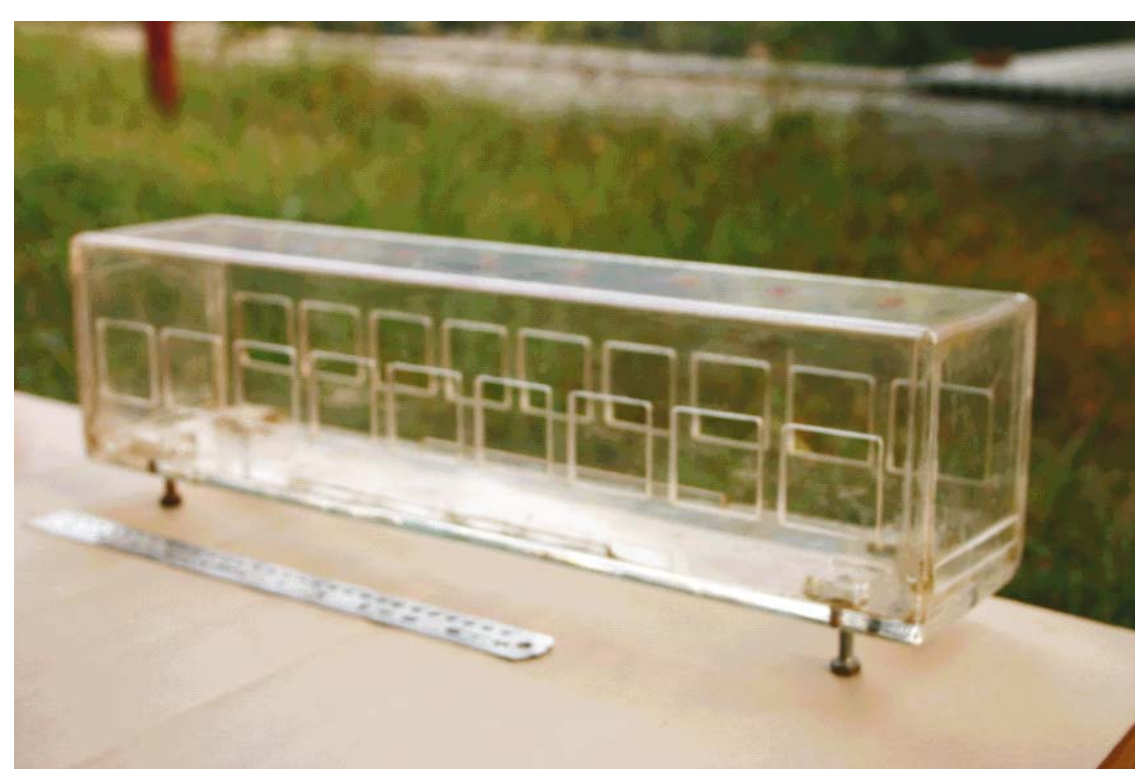

Figure 3. Photograph of the bus model.

\subsection{Water channel experiments}

The experiments were conducted in an open water channel $0.31 \mathrm{~m}$ wide, $0.45 \mathrm{~m}$ high and $11.8 \mathrm{~m}$ long. Water level was set at the maximum possible depth of $0.42 \mathrm{~m}$ with resulting velocity of about $0.6 \mathrm{~m} / \mathrm{s}$. The model width-based Reynolds number in this situation is $0.67 \times$ $10^{5}$ which is an order of magnitude smaller than the actual conditions. The model was bolted to the floor of the channel such that the underside clearance was $0.016 \mathrm{~m}$; in this respect, there is a variation from real motion in that here there is no model-ground relative velocity while actually, the ground should have the same velocity as the free stream. The model was located sufficiently far away from the inlet and outlet of the channel so that the velocity in the vicinity of the bus was uniform.

Flow visualization was performed by injecting coloured water that was produced by mixing potassium permanganate or green/red ink into water. Initial studies showed that interaction of flow with the injection tubes ( $3 \mathrm{~mm}$ outside diameter) generated surface waves that distorted the pictures. This difficulty was overcome by routing the tubes from a point downstream of the portion of interest. Pictures were taken with a digital still camera (maximum shutter speed $1 / 4000$ s) with up to $2 \mathrm{MB}$ per picture.

\subsection{Experiments in a moving bus}

Flow visualization with smoke and tuft were performed in a moving bus on a straight stretch of an open level road and a nominally steady speed of $40 \mathrm{~km} / \mathrm{h}$. The bus had seats but no passengers, the doors were closed and windows adjusted to produce nearly symmetric openings on both sides. The tests were performed when wind was negligible. Smoke patterns from a lighted incense stick were recorded on still and video cameras. Also, wool tufts stuck to a wire were placed at different locations in the windows to identify direction of airflow. Air flow through the roof ventilators that are commonly provided on a bus was also studied. 


\section{Numerical simulations}

Numerical simulations were conducted using Fluent ${ }^{\circledR}$ (Version 6.0). The large eddy simulation (LES) feature of Fluent ${ }^{\circledR}$ was chosen with the RNG based sub-grid scale model. The model constant $\mathrm{C}_{\text {rng }}$ was set to 0.157 for this problem. The bus was modelled as a cuboid with a cross section of $2.5 \mathrm{~m} \times 2.5 \mathrm{~m}$ and length of $12 \mathrm{~m}$. Detailed features are as per the model shown in figure 2; it has nine windows on either side. In the simulation, the windows could be modelled as part of the bus panel or as part of the interior - in this way the windows could be open or closed. The computational domain was $8 \mathrm{~m} \times 8 \mathrm{~m}$ with a length of $45 \mathrm{~m}$. A development length of $12.5 \mathrm{~m}$ was provided upstream of the bus while a larger length of approximately $20 \mathrm{~m}$ was provided on the downstream side to capture the wake region with sufficient accuracy. Usually the re-circulation zone behind a backward facing step extends to approximately 6-7 step heights. Thus, the length downstream of the bus ( 8 bus heights, 8 bus widths) is expected to be sufficient to capture the wake region. The simulations confirm that this is actually the case. A clearance of $0.4 \mathrm{~m}$ was provided between the bottom panel of the bus and the ground and the ground was considered to be stationary.

The mean flow is expected to be symmetric about the $x-y$ plane $(z=0)$ passing through the centre of the bus. Thus, to enable better resolution and to enhance the speed of the computation, only half the domain was solved for and the symmetry condition was imposed at $z=0$. (We note that the imposition of the symmetry condition is not strictly compatible with the unsteady LES calculation adopted here.) A uniform mean velocity of $10 \mathrm{~m} / \mathrm{s}$ with turbulence intensity of $5 \%$ was specified at the inlet while the pressure specified as atmospheric at the outlet plane. The Reynolds number, based on the height of the bus, is thus approximately $1.6 \times 10^{6}$, which is close to the value expected for the actual bus. In the interior of the bus and close to the bus on the outside, the grid size was chosen to be $12.5 \mathrm{~cm}$. while away from the bus the size was relaxed to $0.5 \mathrm{~m}$. The mesh in a region close to the bus is shown in figure 4; farther away the mesh size becomes coarser. In all, for the results shown here, approximately $2 \times 10^{5}$ cells were used. The Kolmogorov microscale, $\eta$, was estimated to be approximately $0.3 \mathrm{~mm}$. Experiments indicate that the smallest scale actually present in turbulent flows is approximately $6 \eta$. Thus, the mesh used here is very coarse, however, as seen below the essential features of the flow are captured quite well even with this coarse mesh. The Kolmogorov time scale, $\tau_{\eta}$ can be estimated to be $6 \times 10^{-3} \mathrm{~s}$. Thus, the time step which was chosen to be $0 \cdot 1 \mathrm{~s}$ is approximately $16 \tau_{\eta}$. The total duration of the calculation was chosen as $25 \mathrm{~s}$, which corresponds to approximately ten integral time scales.

The calculations were conducted on a $3.2 \mathrm{MHz}$ dual processor machine with $2 \mathrm{~GB}$ RAM. Even with the coarse mesh chosen as above the computation time for each of the runs shown here was approximately 6 hours.

\section{Results and discussion}

\subsection{Flow visualization}

Pictures from water channel visualizations are shown in figures 5, 6 and 7 and in all these pictures, the flow is from left to right.

The internal flow in the bus is shown in figures $5 \mathrm{a}-\mathrm{h}$. From the center of the $2^{\text {nd }}$ pair of windows, the flow is towards the front and it exits from the front windows. The flow symmetry is clearly seen in figures $5 \mathrm{a}$ and $\mathrm{b}$ where injected water moves to the front exiting primarily from the $1^{\text {st }}$ windows and to a less extent from the $2^{\text {nd }}$ windows. Similar patterns are also 


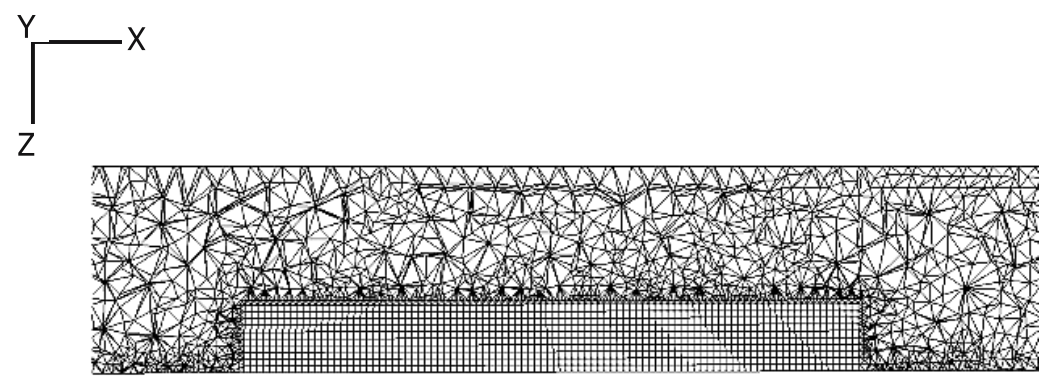

(a) On a horizontal plane at the window mid-height.
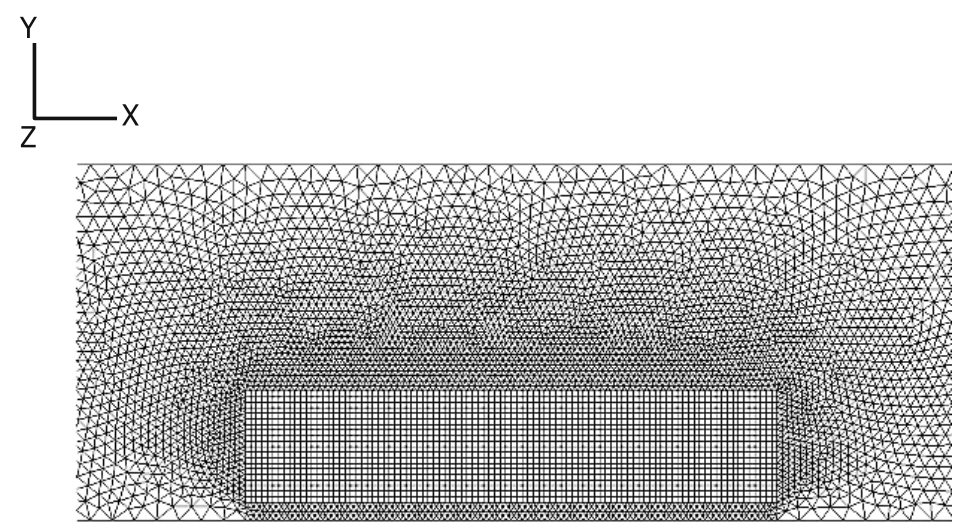

(b) On the vertical plane of symmetry.

Figure 4. The mesh for numerical simulations.

seen in figure $5 \mathrm{c}$ when the coloured solution is injected at the center of the $4^{\text {th }}$ windows. Here, some outflow is seen at the $3^{\text {rd }}$ window while that from the $1^{\text {st }}$ and $2^{\text {nd }}$ windows is less. Injection pattern at the $5^{\text {th }}$ window is seen in figure $5 \mathrm{~d}$. The coloured water flows to the front and exits from the first three windows. There is almost no outflow at the $4^{\text {th }}$ windows. As in the previous three pictures, here too, there is no flow towards the bus rear, i.e. relative to the bus, the internal flow is opposite to the free-stream relative to the bus. The same patterns are observed when injection is at the center of $6^{\text {th }}$ or $7^{\text {th }}$ windows, figures $5 \mathrm{e}$ and $5 \mathrm{f}$, respectively. Flow exits the bus primarily from the first three windows. There is no outflow through the $4^{\text {th }}$ and $5^{\text {th }}$ windows and neither is there any flow towards the bus rear. In figure $5 \mathrm{~g}$, coloured water is injected at the $8^{\text {th }}$ window and it predominantly flows towards bus front and some flows to the rear. The outflow is, however, from the first three front windows only, as seen in the previous pictures. Injection at the far end of the bus through $9^{\text {th }}$ windows is seen in figure $5 \mathrm{~h}$. The coloured water travels right through the entire length of the bus to exit from the front three windows. From these set of pictures, certain aspects of the flow are clearly identifiable. First, the outflow from the bus is from the front three windows. Second, there is no outflow from the rear half of the bus. Third, flow exiting from the front windows does not seem to re-enter the bus. Having identified the outflow patterns, the inflow patterns now call to be identified.

Flow visualization pictures along the side of the bus are shown in figures $6 \mathrm{a}$ to $\mathrm{f}$ each at a different injection point. In figure $6 \mathrm{a}$, the injection point is at the center of the $1^{\text {st }}$ window. The 


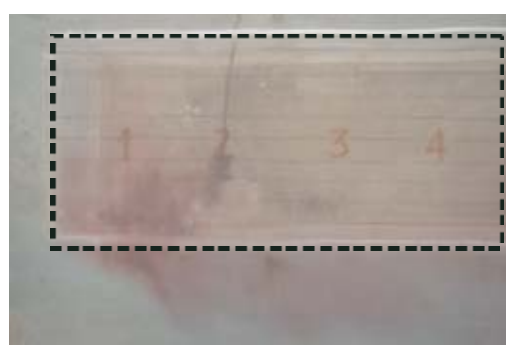

(a) Center of $2^{\text {nd }}$ pair of windows.

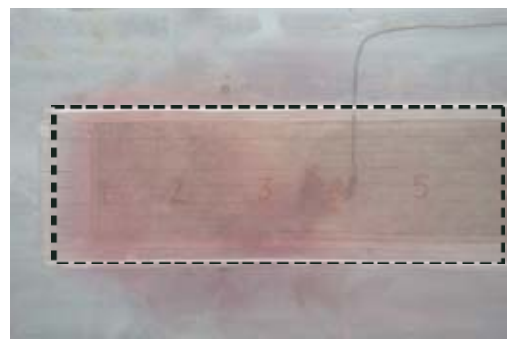

(c) Center of $4^{\text {th }}$ pair of windows.

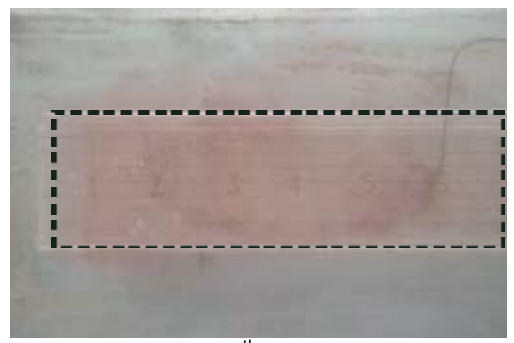

(e) Center of $6^{\text {th }}$ pair of windows.

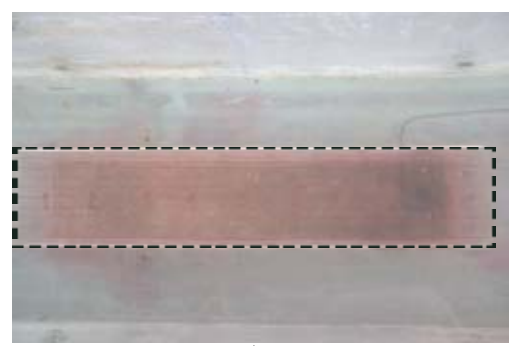

(g) Center of $8^{\text {th }}$ pair of windows.

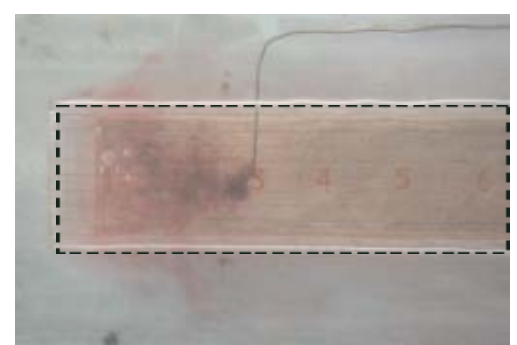

(b) Center of $3^{\text {rd }}$ pair of windows.

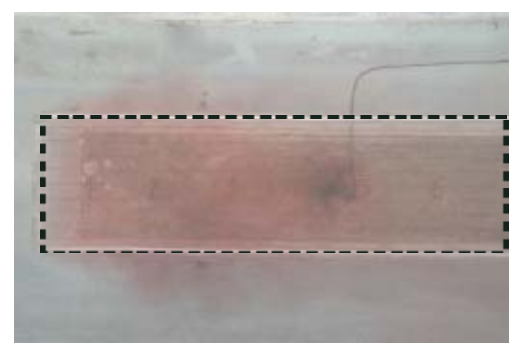

(d) Center of $5^{\text {th }}$ pair of windows.

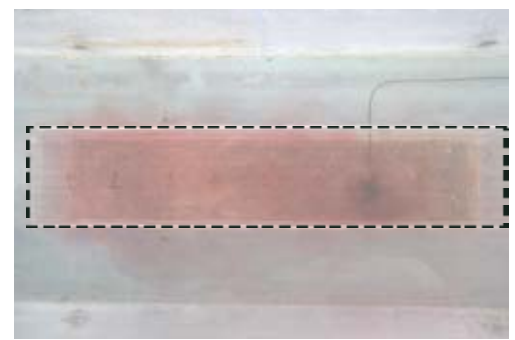

(f) Center of $7^{\text {th }}$ pair of windows.

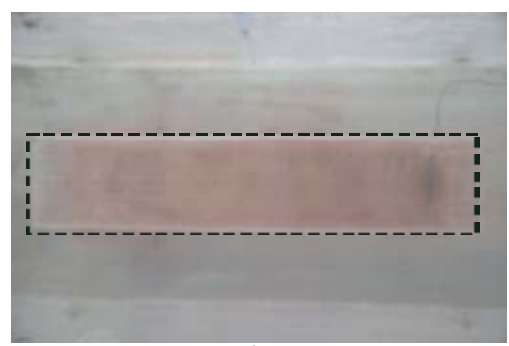

(h) Center of $9^{\text {th }}$ pair of windows.

Figure 5. Flow visualizations with dye injected inside the bus.

picture shows that the coloured water does not enter the bus but flows out. This outflow has two distinct paths, one that moves towards the front edge of the bus along the side wall and then joins the oncoming free-stream flow for its downstream motion. Another portion of the exiting flow directly flows out of the window and then flows downstream towards and away 


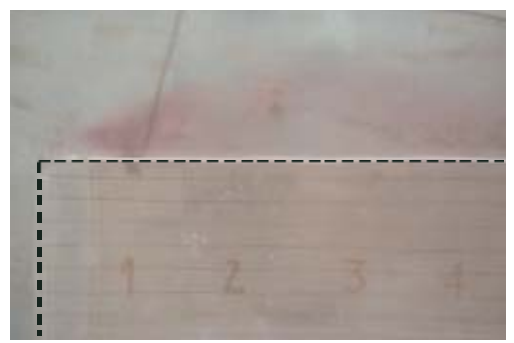

(a) At $1^{\text {st }}$ window

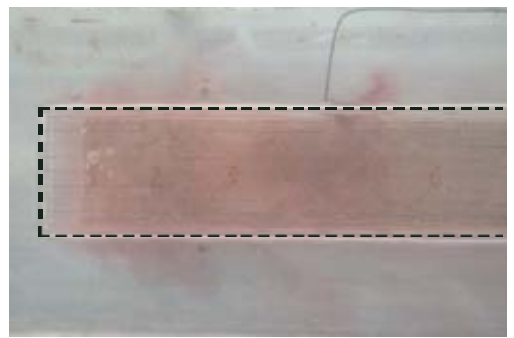

(c) Between $4^{\text {th }} \& 5^{\text {th }}$ windows

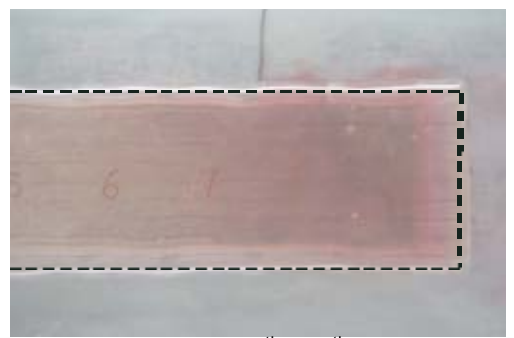

(e) Between $7^{\text {th }} \& 8^{\text {th }}$ windows

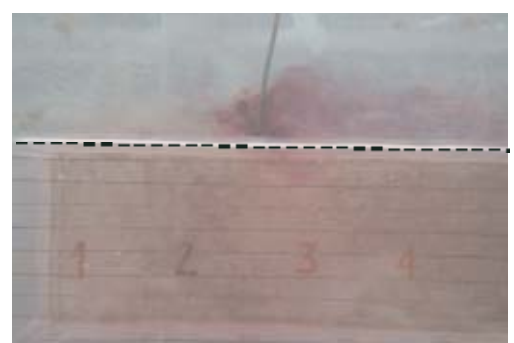

(b) Between $2^{\text {nd }} \& 3^{\text {rd }}$ windows

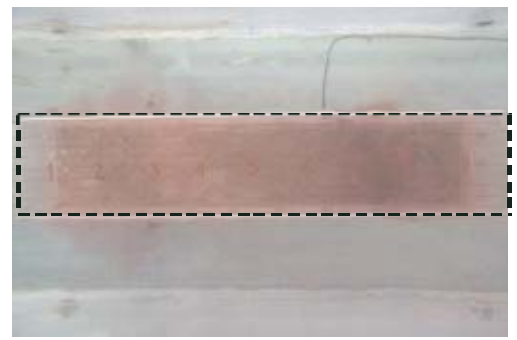

(d) Between $6^{\text {th }} \& 7^{\text {th }}$ windows

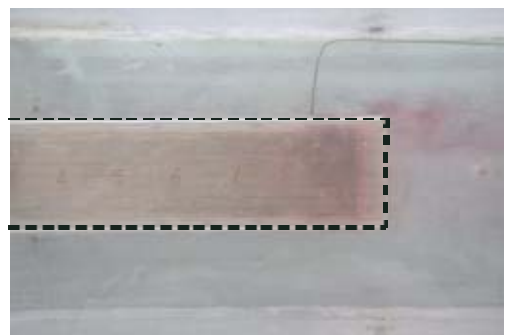

(f) At $9^{\text {th }}$ window

Figure 6. Flow visualizations at the outside wall and at the window.

from the $2^{\text {nd }}$ window. Coloured water injected at the wall between $1^{\text {st }}$ and $2^{\text {nd }}$ windows, shows that all of this water flows outwards from the $2^{\text {nd }}$ window as well as from the $3^{\text {rd }}$ window (figure 6b). The spread indicates bi-directional dispersion with flow towards the bus front and towards the bus rear. Exiting dye from the first two windows was also observed to move

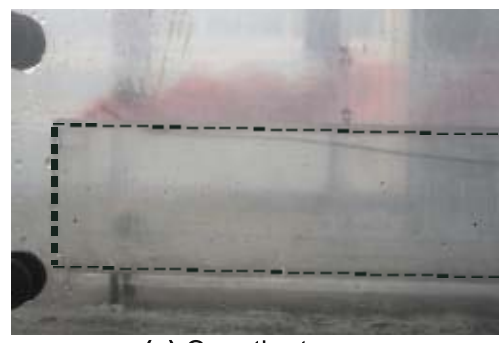

(a) Over the top

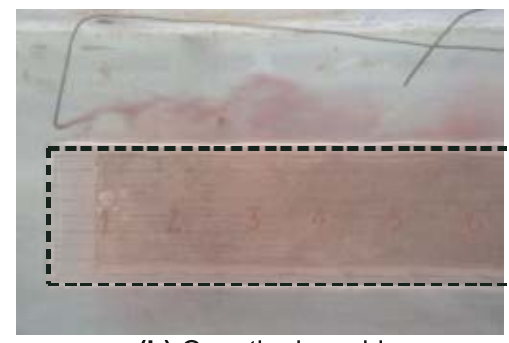

(b) Over the bus side

Figure 7. Flow visualizations with dye injected over the bus top and sides. 
upwards along the bus side to the roof top. Figure $6 \mathrm{c}$ shows dispersion from an injection point between the $4^{\text {th }}$ and $5^{\text {th }}$ windows. Most of the coloured water enters the bus through the $5^{\text {th }}$ window, none through the $4^{\text {th }}$ window, and a small amount moves downstream and away from the window. Coloured water that enters the bus is seen to move forward through the bus and exit from the first two rows of windows, as seen in figures $5 \mathrm{c}$ to $5 \mathrm{f}$. The $3^{\text {rd }}$ window neither has inwards nor outwards flow. Injection between $6^{\text {th }}$ and $7^{\text {th }}$ windows, figure $6 \mathrm{~d}$, shows that almost all the coloured water enters the bus and a small amount flows downstream in a region adjacent to the bus exterior and enters the bus through the next window, the $8^{\text {th }}$. Thus, all the coloured water enters the bus, after which it follows the earlier described path towards bus front and exit from the front two windows. None of this exiting water is seen to re-enter from the rear as it has dispersed. Figure $6 e$ shows the flow with injection between $7^{\text {th }}$ and $8^{\text {th }}$ windows. Bulk of the flow is seen to enter the bus with a small amount moving towards bus rear along the exterior. Almost all the flow entering the bus moves towards the bus front as before, and a small amount is seen to exit from the rear edge of the $9^{\text {th }}$ window. Figure $6 f$ shows that coloured water injected between the $8^{\text {th }}$ and $9^{\text {th }}$ windows enters the bus and some of it moves past the window face to the bus rear and into the wake region.

Figures $7 \mathrm{a}$ and $\mathrm{b}$ show the external flow over the bus from the top and side. In figure $7 \mathrm{a}$, coloured water is injected at the bus front face and the picture is taken from a side and shows the flow above the bus roof. A re-circulation region is visible that extends up to about the location of the $5^{\text {th }}$ window, i.e. up to about $50 \%$ of the bus length. In figure $7 \mathrm{~b}$, taken from the top, the injection point is at the front face but spaced slightly away to a side at midwindow height. The coloured streak disperses gradually and at about the $4^{\text {th }}-5^{\text {th }}$ windows an accumulation is seen. This region is the low velocity reversing flow that occurs at the center of the re-circulation region. The re-attachment point is almost at the rear end of the bus.

From the above, a composite sketch of the flow at a horizontal plane centered on the midheight of the windows has been prepared and is shown in figure 8 . The most prominent feature of this flow is the forward motion of air inside the bus, relative to the bus; this motion is opposite to the direction of the free-stream flow. The magnitude of this flow is estimated to be an order of magnitude less than the free-stream velocity. The entire side of the bus, at this level, has a re-circulation region that is in contrast to the bus top where the re-circulation region length is about $50 \%$ of the bus length. Air enters through the rear windows, $5^{\text {th }}$ to $9^{\text {th }}$, and exits through the front windows, $1^{\text {st }}$ and $2^{\text {nd }}$. In the middle windows, $3^{\text {rd }}$ and to some extent $4^{\text {th }}$, air velocities are very small with the direction normal to the window fluctuating. These general features were also observed in the smoke and tuft visualizations carried out on a real bus traveling at about $40 \mathrm{~km} / \mathrm{h}$. The implications for the public at large are that passengers sitting near the windows in the rear will experience fresh air from outside while those at the front will experience air flowing outwards from within. All flows are three-dimensional and turbulent. The videographs of these experiments showed that the high level of turbulence in the flow ensures that the same air does not keep circulating in and out, but is thoroughly dispersed and mixed with fresh air from the front.

\subsection{Computer simulations}

Figure 9 shows the distribution of the mean flow in the symmetry plane $(z=0)$. The colours indicate the magnitude of the mean velocity vector. Two regions of separated flow are clearly seen in this view - one on the top surface of the bus and one in the rear. The separated zone on the top surface extends to a distance approximately $8 \mathrm{~m}$, which is approximately three times the height of the bus. The flow pattern downstream of the separated zone shows the flow 


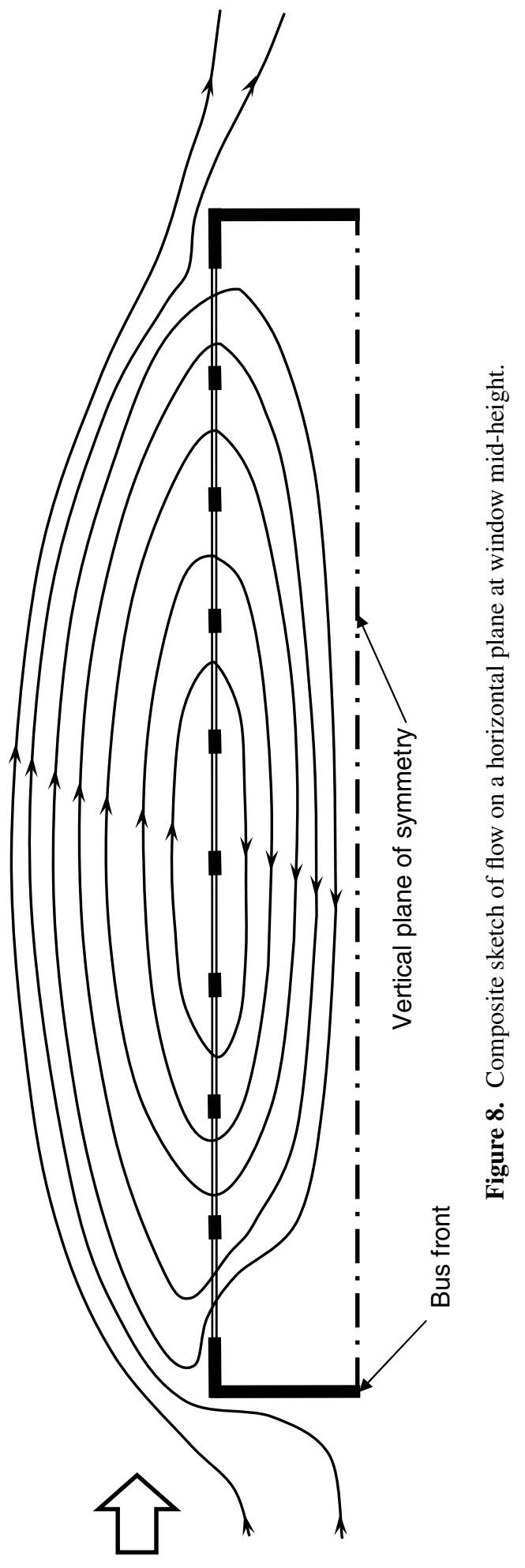


moving up and then turning downstream. This pattern is indicative of the three-dimensional nature of the flow and is discussed in greater detail below. The second separated zone seen in this view is in the wake of the bus. This region extends up to approximately $5 \mathrm{~m}$, which is twice the height of the bus. This separated region is seen to consist of two re-circulating zones. The upper zone is larger and more intense. This asymmetry is expected due to the presence of the ground. The velocity magnitude inside the bus is roughly $1 / 10^{\text {th }}$ of the inlet velocity which matches well with the results of the flow visualization experiments discussed above. Two regions of accelerated flow are also seen in this figure - one at the end of the favourable pressure gradient region created by the separation bubble and the second between the bus and the ground. We note here that the simulations were conducted with the ground at rest. More accurate simulations could be obtained by making the ground move in the $\mathrm{x}$ direction at the same speed as the free-stream velocity. However, as seen from the discussion below this region is not very critical to the overall dynamics of the flow.

Figure 10 shows the velocity vector plots in the $x-z$ plane at the level of the window centres $(y=1.9 \mathrm{~m})$. Again, the colours indicate the magnitude of the mean velocity vector. It is clearly seen in this view that the interior of the bus is part of the re-circulating zone. Air enters the bus from the rear windows (6, 7, 8 and 9) and exits from the front windows (1, 2 and 3). Windows 4 and 5 lie in the central region and the air is nearly at rest here. The fluid exiting from windows 1 and 2 travels up towards the separation point and then turns and flows towards the rear of the bus. The qualitative sketch prepared on the basis of the flow visualization pictures (figure 8) agrees well with the flow pattern seen here. Since the flow is turbulent there is mixing between the fluid in the re-circulation region and in the external flow, otherwise given the mean flow pattern here there would be very little fresh air entering the bus.

Figures $11 \mathrm{a}, \mathrm{b}$ and $\mathrm{c}$ show the flow in the $y-z$ plane at different $\mathrm{x}$-locations corresponding to the mid planes of $1^{\text {st }}, 4^{\text {th }}$ and the $9^{\text {th }}$ windows respectively. The colour indicates the magnitude of the vertical (v) component of the velocity here. Figure 11a shows the flow clearly exiting from the $1^{\text {st }}$ window. The three-dimensional nature of the flow over the bus is also clearly seen in this figure. In the region close to the window a part of the flow moves downwards, however, a large fraction moves upwards in tune with the external flow which shows a broad motion upwards due to the deflection of the flow by the top panel of the bus. Figure 9 shows that the external flow is aligned with $\mathrm{x}$-direction beyond the $3^{\text {rd }}$ window. Thus, in figure $11 \mathrm{~b}$, which shows the flow in the mid plane of the $4^{\text {th }}$ window, the (in-plane) velocity magnitudes are seen to be negligible away from the bus. A small amount of air is seen leaving from the centre of the window. The flow in the interior of the bus is in the form of two nearly symmetric eddies. A weak vortex is also seen adjacent to the bus above the centre of the window. Figure 11c shows the flow pattern at the rear end of the bus, in the mid plane of window 9. As in figure $11 \mathrm{~b}$, this figure also shows that away from the bus the (in-plane) velocity magnitudes are negligible. There is inward flow throughout the face of this window, while in the interior of the bus the flow splits into two nearly symmetric eddies. The vertical motion seen adjacent to the bus in figure 11a is absent here.

\subsection{Studies on a running bus}

Smoke movement with the incense stick at several locations along bus length showed distinctly that air flow was from rear to front. The speed measured with a Vane Anemometer was about $1-2 \mathrm{~m} / \mathrm{s}$. At the two rear windows, a continuous inflow was observed while at the front window, an outflow was seen. In the middle windows, no clear pattern could be observed as the velocity magnitudes were small and direction was alternately inwards and outwards. 


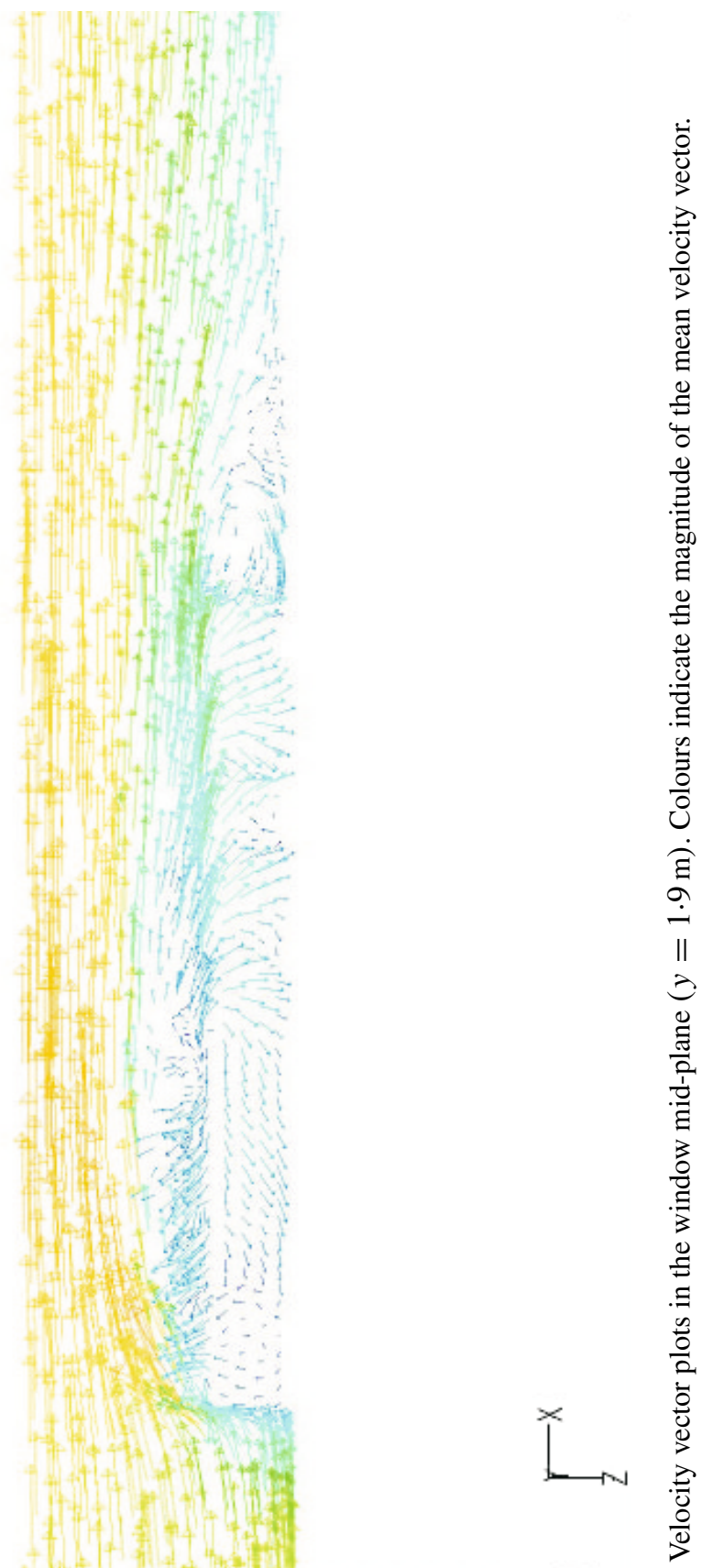

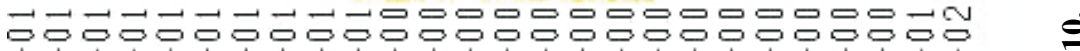

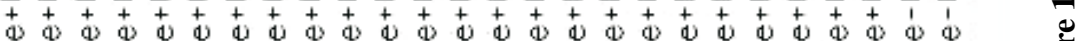

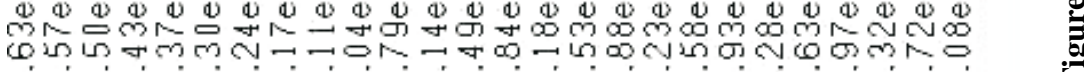

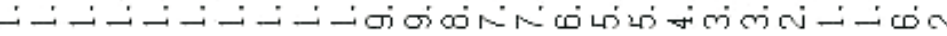



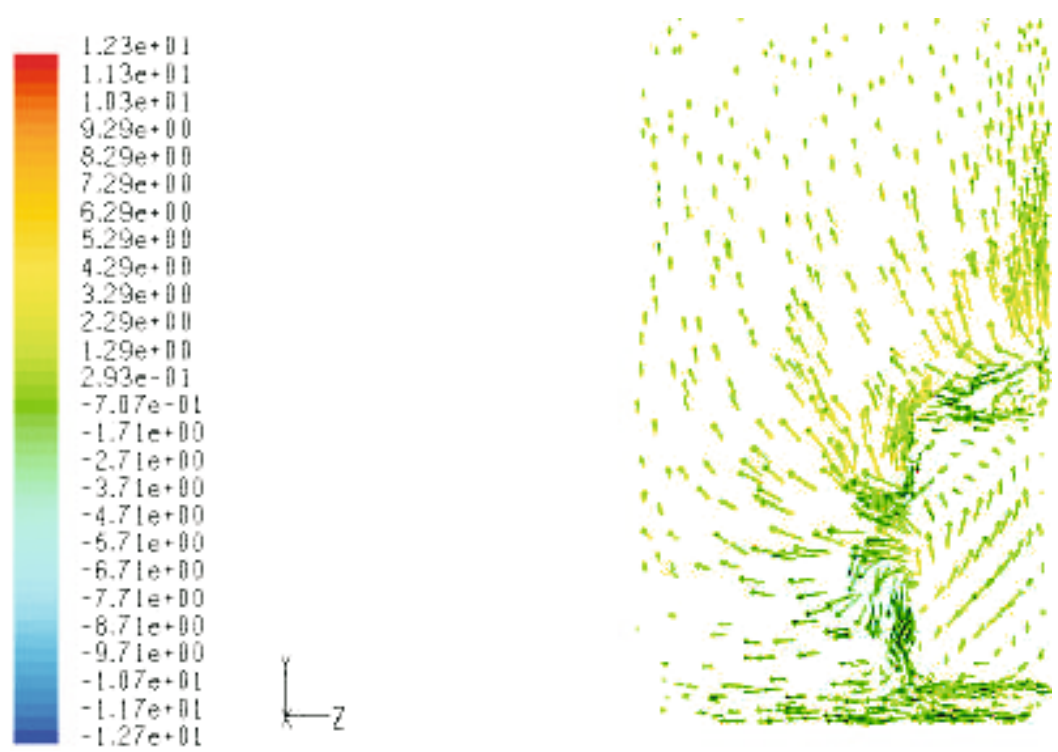

Figure 11(a). Velocity vector plot in the $y-z$ plane in the middle of window 1 . Colours indicate the magnitude of the vertical velocity component.

A steady outflow was observed at the front roof vent that was located above the driver's seat (figure 1). At the second opening that was located about a third from the front (figure 1), a medium velocity inflow (about $4-5 \mathrm{~m} / \mathrm{s}$ ) was observed. These observations are in agreement with the numerical simulations as well as the laboratory visualization experiments.

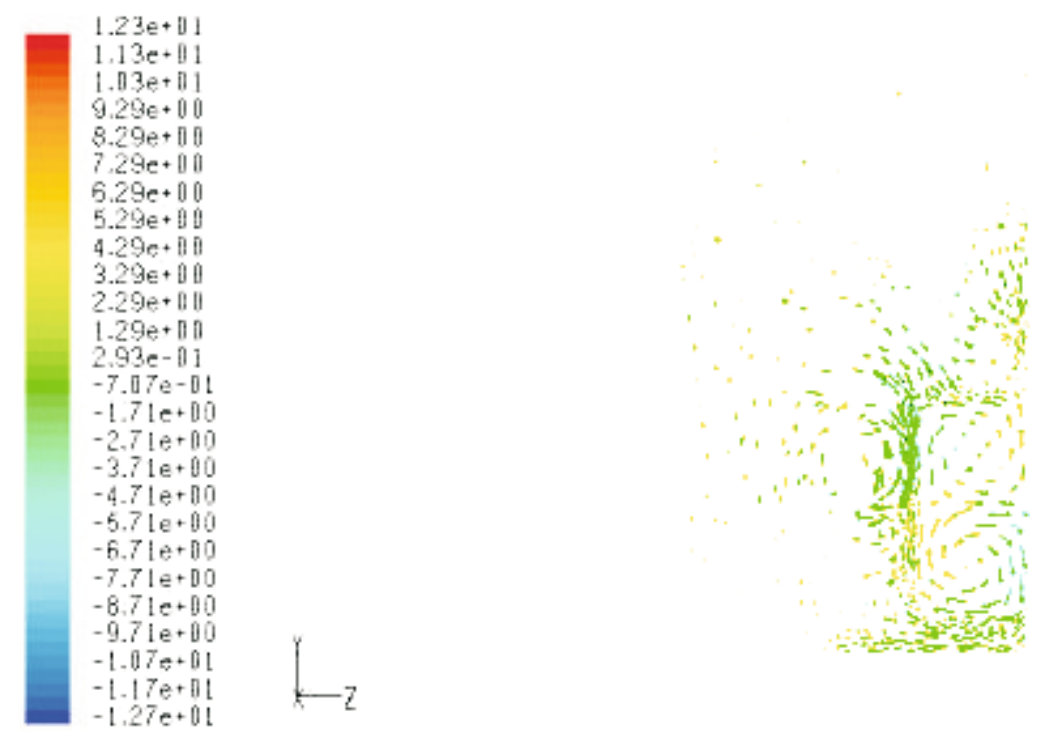

Figure 11(b). Velocity vector plot in the $y-z$ plane in the middle of window 4 . Colours indicate the magnitude of the vertical velocity component. 


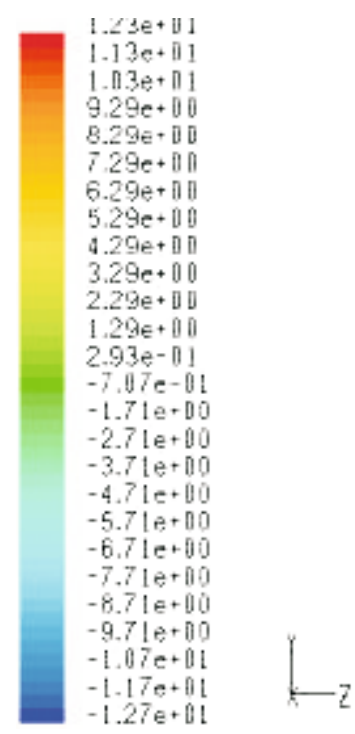

Figure 11(c). Velocity vector plot in the $y-z$ plane in the middle of window 9. Colours indicate the magnitude of the vertical velocity component.

\section{Conclusions}

The studies show that flow inside a bus with open windows is complex. Outside air enters the bus from the rear windows, moves forward relative to the bus at about $1 / 10^{\text {th }}$ the bus speed and exits from the front windows. The size and nature of the re-circulation regions on the side and top are different. Although the Reynolds numbers for water channel tests and numerical simulations differed, the agreement in respect of broad flow characteristics, qualitative and quantitative, was good. This study forms a basis for further investigations on the effects of roof and side vents, fans and blowers, window design and setting changes, thermal effects, and passenger loading, as well as less expensive methods for airconditioning. The study can also be extended to road dust entrainment and fire safety of such buses.

The assistance of Mr Sanyog Yadav and the staff of Fluid Mechanics Laboratory, Department of Applied Mechanics, IIT Delhi are gratefully acknowledged.

\section{References}

Abdel Azim El-Safed A E, Nassief M M 1996 Investigation into the aerodynamics of the external flow around a bus (Daewoo model) SAE Special Publications 1199: 59-68

Kim M-H 2004 Numerical study of the wake flow, characteristics and drag reduction of large sized bus using rear spoiler Intl. J. Vehicle Design 34(3): 203-217

Krajnovic S, Davidson L 2003 Numerical study of the flow around a bus-shaped body Trans ASME J. Fluids Engg. 125(3): 500-509

Lajos T, Preszler L, Finter L 1998 Styling and aerodynamics of buses Intl. J. Vehicle Design 9(1): 1-15 
McCallen R, Browand F, Ross J 2002 The aerodynamics of heavy vehicles: Trucks, buses and trains (New York: Springer)

Nakanishi T, Shimoda S, Yamasaki N, Inokuchi Y, Takemoto T, Okazawa, H, Namba M 2000 Numerical and experimental methods to investigate cooling air flow in the construction machinery's engine compartment SAE 2000-01-2577

Ohshima T, Hamatani K, Ninoyu M, Nakagawa, K 1998 Influence of the cooling air flow outlet on the aerodynamic characteristics JSAE Rev. 19: 137-142

Saunders J W, Watkins S, Hoffmann P H, Buckley F T 1985 Comparison of on-road and wind tunnel tests for tractor-trailer aerodynamic devices and fuel savings predictions SAE 850286 